\title{
Whatever the Kid Does Is the Truth: Introduction to the Special Section on Direct Instruction
}

\author{
William L. Heward ${ }^{1}$ (D) Janet S. Twyman ${ }^{2}$ \\ Accepted: 11 August 2021/ Published online: 30 August 2021 \\ (C) Association for Behavior Analysis International 2021
}

Direct Instruction (DI) is a powerful teaching system that combines logical analysis and testing of the content students are to learn, thoughtful selection and sequencing of instructional examples, clear communication between teacher and student, high rates of student engagement, reinforcement and corrective feedback, judicious review, and practice to mastery. The procedures we now know as DI originated in the 1960s with instruction designed to teach highly at-risk students at the Bereiter-Engelmann Preschool, at the University of Illinois (Bereiter \& Engelmann, 1966). The ensuing philosophy of instruction and applied research with young children lead Siegfried Engelmann and Wesley Becker to develop DISTAR Reading (Direct Instruction System of Teaching and Remediation), the first formal DI program, and served as the foundation for all the DI programs that followed.

Across decades the model has been further developed by Engelmann, Doug Carnine, Ed Kame'enui, Jerry Silbert, and others at the University of Oregon. We refer to DI as the model representing the numerous critical features that every DI program employs. However, DI is much more than a collection of effective practices. It's also a model in the sense of the rigorous design-test-redesign development process, one that has evolved as a result of careful investigations of efficacy and parametric analyses of effectiveness. Over time DI has evolved in at least three directions: the abilities and characteristics of the students served, the content and subject matter taught, and the refinement of the logic and practices that make up DI. Ideas around these evolving directions are reviewed in this special section.

Siegfried "Zig" Engelmann devoted his life to designing instructional programs that accelerate children's learning. He was convinced that given the right instruction, all children could learn. As Skinner's epistemological touchstone,

William L. Heward heward.1@osu.edu

1 Ohio State University, Columbus, OH, USA

2 blast (a learning sciences company), Cottonwood, AZ, USA 
"The rat is always right," helped Skinner stay on target, Zig's steadfast belief that "Whatever the kid does is the truth!" drove an unwavering commitment to the learner's behavior as the prime determinant of instructional efficiency (see Heward et al., 2021). Engelmann's discoveries of how to teach more in less time are of paramount social significance and no less groundbreaking than Lovaas's demonstrations of how systematic, intensive instruction could improve the lives of children with autism.

An invited symposium at the Association for Behavior Analysis International's 2020 annual convention titled “Siegfried Engelmann's Direct Instruction: Faultless Communication, Measurably Superior Learning, and the Quest for Widespread Adoption" was the impetus for this special section. A subsequent call for papers produced an impressive collection of articles that review Engelmann's achievements as a pioneering scientist, examine the DI research base, and explore how DI's theory of instruction and application are harmonious with behavior analysis.

The September issue of Behavior Analysis in Practice includes a companion special section on DI (Heward \& Twyman, 2021). Articles in the BAP special section describe how behavior analysts can incorporate DI and its essential features into their practice.

\section{Who Was Siegfried Engelmann?}

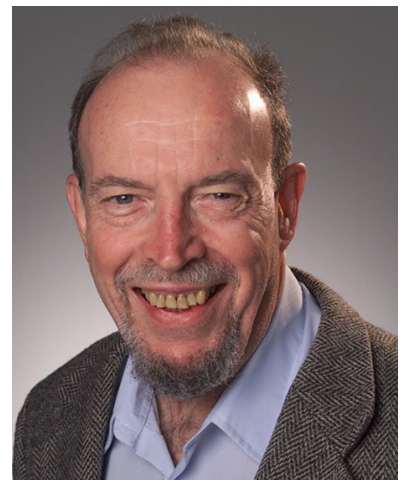

\section{Siegfried "Zig" Engelmann (1931-2019)}

"If the student hasn't learned, the teacher hasn't taught — that's not a slogan, it's an operating principle (see Barbash, 2012)."

In "Science in the Service of Humanity: The Astonishing Contributions of Siegfried Engelmann," Shep Barbash reviews the pioneering scientist and educator who "stood alone for his ability to create programs that accelerate learning in even the hardest to teach children." Engelmann's long-time colleague and co-author Doug Carnine called Barbash's article "a brilliant bringing-to-life the person Zig Engelmann. It is the weaving together of Zig's genius and his humanity that makes this such a significant contribution" (with permission from author and reviewer). 


\section{Direct Instruction and Educational Equity}

Schools have notably, consistently, miserably, and relentlessly failed students. The disparity in academic achievement between minority and poor children and their more affluent peers is so long standing that it has come to be expected and accepted. . . . Every social justice advocate, indeed, every American should be outraged about the dismal performance of American schools, particularly with regard to diverse learners. (From Ralph Gardner's review of Jean Stockard's article in this issue. Used with permission from author and reviewer)

Gardner's statement underscores the importance of Jean Stockard's paper, "Building a More Effective, Equitable, and Compassionate Educational System: The Role of Direct Instruction." Stockard writes DI could, and should, be a key element in transforming our educational system to address the issue of low achievement and building the more compassionate society envisioned by Anthony Biglan (2020).

Direct Instruction has its roots in providing effective instruction for at-risk children, in particular children of poverty (Engelmann, 2007) and this concern has continued as DI has evolved. Stockard reexamines a recent large meta-analysis of research showing that DI is not only more effective than other educational approaches, but it also produces effect sizes that overcome the achievement gap often experienced by students from lower income homes. Although recognizing powerful actors within the educational establishment have opposed DI and hidden evidence of its effectiveness, Stockard identifies other social actors who could work together to counter this control and build an educational system that promotes the well-being of all.

\section{Direct Instruction: Under the Hood}

The data are in: DI works. Yet, how does it work? How does DI enable teachers to teach more to more learners in less time? The key is an adherence to a logical, coherent, and testable (i.e., falsifiable) theory of instruction. In his Foreword to the revised edition of Engelmann and Carnine's (1991) tour de force text detailing the theory and logic of DI, Robert Dixon (1991) wrote:

First and foremost, Theory of Instruction is the articulation of a theory - not in the atheoretical sense "theory" is used in educational jargon, but in the more precise sense well-established among scientists and philosophers of science.

Engelmann and Carnine's theory evolved the same way original natural science theories have evolved, through the scrupulous application of logical analysis to existing empirical observation. The Engelmann and Carnine theory possesses the most critical attributes of natural science theories: (1) it is exhaustive in that it covers everything from the most basic motor skill instruction to the highest of the "higher order" thinking skills, and (2) it does so economically. In short, it is parsimonious. ... (p. i)

A true theory not only predicts, it explains. For example, if we are interested in why cognitive psychologists have, after several years of research, concluded that 
the extent to which learning transfers is dependent upon the relative salience of surface and structural features of examples, this theory will explain that for us. If we are interested in why a typical textbook presentation of a new concept must fail to communicate accurately to many learners, this theory will explain that, too. ... (p. ii; emphasis in original)

Two articles by Janet Twyman examine the theoretical constructs and behavioral principles that make DI programs so powerfully effective. "Faultless Communication: The Heart and Soul of DI" opens with sobering statistics about society's failure to provide the majority of children around the world with a basic education and offers reasons why effective educational practices such as DI and those informed by behavior analysis are not more widely adopted. Twyman examines a particular component of DI in "Faultless Communication," and relates it to findings from the behavior analytic literature, showing not only great overlap and consistency in findings, but also that synergies exist that would make combined research and application efforts greater than the sum of the parts. Twyman describes the powerful improvements possible from well-designed instructional sequences (communications) as defined by DI then offers suggestions on how behavior analysts may benefit from this component.

In "The Evidence Is in the Design," Twyman examines the empirical base related to DI's design components and instructional principles and concludes there is ample evidence for DI as an evidence-based practice (through and through). The converging evidence reveals DI's rigor as a scientifically evaluated program, and just as important, a scientifically developed program. A commitment to logical thinking underlies the DI principles and procedures elucidated in Engelmann and Carnine's (1991) Theory of Instruction. However, logic by itself was (and still is) insufficient for developing a cohesive, workable, effective instructional technology. Empirical validation is vital. Engelmann (2009) reported that as DI was being developed, each time the authors formulated a principle, strategy, or tactic, they asked each other, "Do you know of any studies confirming this?" Nine times out of 10 the answer was no, so they conducted experiments. Their commitment to building a research program dedicated to evidence-based teaching serves as a model for many in our field: we must continue to research and develop.

\section{How Effective Is Direct Instruction?}

Steadfast belief in the motto, "If the student has not learned, the program has not taught" (Barbash, 2012, p. 2) has motivated DI developers and researchers to craft rigorously designed and field-tested programs for teaching reading, math, writing, spelling, and thinking skills to children. A DI program is not published until the lowest performing students master at least $90 \%$ of the skills taught in the program, a stunning criterion.

That level of R\&D sounds good, but a properly skeptical behavior analyst wants to know: Is there peer-reviewed scientific evidence showing DI programs work as well in the classroom as they do during development and field-testing? And what's the quality of that evidence? The answer: more high quality, peer-reviewed evidence attests to DI's 
effectiveness than for any other educational approach, curriculum, or program (Stockard et al., 2020).

In "Just How Effective is Direct Instruction?" Lee Mason and Maria Otero examine the DI evidence base through the lens of binominal effect-size displays (BESD), which they contend convey the real-world importance of treatment outcomes the relative proportions of success. The BESD of results from one meta-analysis led the authors to conclude DI benefits an additional 44 per 100 students over the other curricula that were reviewed in the meta-analysis. Regardless of background, DI increased academic achievement from $28 \%$ to $72 \%$. Summoning Skinner's (1968) Idols of the Good Teacher and of the Good Student, Mason and Otero conclude, "Despite having never been widely embraced or implemented, the large body of evidence supporting the effectiveness of DI has elevated it to education's empirical benchmark of comparison. Perhaps it is time to acknowledge that DI has situated itself as the Idol of the Good Curriculum".

"A Systematic Review and Quality Appraisal of Applications of Direct Instruction with Children with Autism Spectrum Disorder" by Sarah Frampton, Greg Munk, and Alice Shillingsburg synthesizes findings of 16 studies evaluating DI with learners with ASD. The article addresses the contributions of the studies to date and identifies additional areas of research that may lead to more learners with ASD benefitting from bring DI. And make recommendations for where research is needed to extend DI to this and perhaps other populations.

\section{Measuring Explicit Instruction}

In "Measuring Explicit Instruction with the Classroom Observations of StudentTeacher Interactions (COSTI)," Barbara Gunn, Keith Smolkowski, Lisa Stryker, and Caroline Dennis present a tool for measuring the frequency and rate of explicit instructional interactions such as those used in DI curricula (e.g., providing independent practice, corrective feedback). The authors describe the development and technical adequacy of the COSTI, discuss its potential use in training and coaching teachers to use explicit instructional methods, and outline a research agenda to improve the COSTI and related observation tools.

\section{A Commitment to Falsifying One's Own Thinking}

In "Ode to Zig (and the Bard): Toward a More Complete Logical-Empirical Model of Direct Instruction," Edward Kame'enui hypothesizes that Engelmann's thinking about the schooling environment provoked his theoretical, philosophical, and conceptual insights into the design of DI. According to Kame'enui, Engelmann's “fierce and unflinching commitment to the learner as the ethical imperative" drove him to seek answers to two fundamental questions:

First Question: What in the school environment is the learner, as an inexperienced and guileless observer of the world, required to negotiate 
on a moment-to-moment basis that sets the stage for his or her success or failure in school?

Second Question: What in the learner's school environment can a teacher control, engineer, and take full and direct responsibility for to increase the oddssignificantly so - that the learner will be successful?

Kame'enui contends that features and elements important to the fabric of DI are Shakespearean in nature because they conceal more than they reveal. "In Engelmann's Direct Instruction, as in Shakespeare's work, conceptual and analytical hooks are threaded throughout its fabric for the benefit of the teacher, yet purposefully designed to privilege the learner's success".

Kame'enui concludes his Shakespearian-inspired look at DI by predicting that if Zig could speak now to those claiming interest in improving education, he would remind us to keep our focus on the "type of learning that is caused by teaching" (Engelmann \& Carnine, 2011, p. 11) and demand we continually challenge ourselves to falsify, revise, improve, and perfect the design of instruction until all children succeed.

\section{How to Get Educators to Use DI}

Pat Friman's "Dissemination of Direct Instruction: Ponder These While Pursuing That" concludes the special section. The article begins with a most reasonable question: If Direct Instruction is one the most effective methods ever invented for educating children, why hasn't the entire education community adopted it? Friman compares DI proponents' predicament to behavior analysts' long-standing complaints and head scratching over why doesn't society use our good stuff? Disseminating DI in particular, and behavior analysis in general, says Friman, would be improved by attending to five things: social validity, marketing, being behavior analytic, the behavioral dynamics of training, and politics. He suggests that failure to address any of these supplies a partial answer to the question initially posed by Skinner and subsequently by like-minded behavior analysts and DI advocates: We happy few, but why so few?

After reminding those trying to make the world a better place by transforming the quality of education for all children that they are up against ways of thinking about human behavior "buttressed by 1000 s of years of cultural instantiation," Friman provides some comfort with this paraphrase of Martin Luther King, "the arc of the educational universe bends towards child learning and well-being."

\section{The Job Before Us}

Although the core logic, developmental testing, foundational teaching practices, and steadfast commitment to student learning on which DI is founded have not changed greatly since inception, the DI model continues to evolve. Components of DI have been adapted to meet the needs of learners receiving special education services (Marchand-Martella et al., 2005) including learners with autism (Vidovic et al., 2021). DI has been combined with other teaching or measurement models, such as 
behavioral skills training (Sherman et al., 2021) and Precision Teaching (Binder \& Watkins, 1990).

As with any evolving framework, there remain questions to be asked and answers to be found. How well is DI's underlying logic understood behaviorally, mechanistically, or otherwise? With all its documented success, what further research and analyses could be done to understand the conditions necessary for widespread adoption? What else can we learn about the necessary and sufficient conditions for teacher training and administrator support? Can research show that intangible attributes like grit, resilience, and self-esteem can arise from good teaching and successful learning? How far can a DI program take a learner? How far can we stretch DI principles and procedures beyond their extremely valuable contributions academic and language foundations and understanding concepts and big ideas?

The articles in this special section and the companion set of articles in the September 2021 issue of Behavior Analysis in Practice address some of these questions or at least stimulate thinking around them. We hope the two special sections raise awareness of, appreciation for, and interest in DI, and spur research and action among those committed to improving education and society. If all of us work more closely, collaboratively, and effectively across the learning sciences, then Engelmann's lifelong dream that every child receives an effective education will move a bit closer to reality.

\section{Acknowledgements}

This special section is the direct outcome of the contributions and collaborative efforts of many. Editor-in-Chief Chris Newland approved our proposal and provided much-needed support and guidance throughout. A special tip of the cap to Kurt Engelmann and Bryan Wickman at the National Institute for Direct Instruction (www.nifdi.org) for sharing their knowledge and providing several photos and figures.

We are especially grateful to the 27 scholars, scientists, behavior analysts, and educators who reviewed submissions (see below). The reviewers' expertise and insights improved each submission (some which will be published elsewhere) and helped us to determine those most deserving of inclusion in this special section. We thank all of the authors who responded to the call for papers. This special section is the product of their expertise and passion for effective instruction. Many fine papers were submitted, and we are pleased to present you with these selected few.

\section{Reviewers for the Special Section Direct Instruction}

\section{Perspectives on Behavior Science}

David F. Bicard, Great Leaps Learning Center

Anthony Biglan, University of Oregon

John C. Borreo, University of Maryland, Baltimore County

Doug Carnine, University of Oregon

David J. Chard, Boston University

Thomas S. Critchfield, Illinois State University

Edward Daly, University of Nebraska

Ronnie Detrich, Utah State University

Sigmund Eldevik, Oslo Metropolitan University

Ralph Gardner III, Ohio State University

Charles R. Greenwood, University of Kansas

Per Holth, Oslo Metropolitan University 
Charles A. Hughes, Penn State University

Edward J. Kame'enui, University of Oregon

Jonathan W. Kimball, Behavior Development Solutions and Maine Behavioral Healthcare

Martin Kozloff, University of North Carolina at Wilmington

Danielle LaFrance, H.O.P.E. Consulting, LLC

T.V. Joe Layng, Generategy, LLC

John Wills Lloyd, University of Virginia

Neil Martin, Behavior Analyst Certification Board

Glen L. McCluller, Stephen F. Austin State University

Robert C. Pennington, University of North Carolina Charlotte

Steve Osborn, textbook author, McGraw Hill Education

Timothy A. Slocum, Utah State University

Jean Stockard, University of Oregon

Matt Tincani, Temple University

Jason C. Travers, University of Kansas

Cathy L. Watkins, California State University, Stanislaus

\section{References}

Barbash, S. (2012). Clear teaching: With Direct Instruction, Siegfried Engelmann discovered a better way of teaching. Education Consumers Foundation. http://www.education-consumers.org/CT_111811.pdf

Bereiter, C., \& Engelmann, S. (1966). Teaching disadvantaged children in the preschool. Prentice Hall.

Biglan, A. (2020). Rebooting capitalism: How we can forge a society that works for everyone. Values to Action.

Binder, C., \& Watkins, C. L. (1990). Precision teaching and Direct Instruction: Measurably superior instructional technology in schools. Performance Improvement Quarterly, 3(4), 74-96.

Dixon, R. (1991). Foreword. In S. Engelmann \& D. W. Carnine, Theory of instruction: Principles and applications (Rev. ed.; pp. i-iii). ADI Press.

Engelmann, S. (2007). Teaching needy kids in our backward system: 42 years of trying. ADI Press.

Engelmann, S. (July 2009). The theory of Direct Instruction. Keynote presentation at the 35th National Direct Instruction Conference and Institutes, Eugene, OR.

Engelmann, S., \& Carnine, D. W. (1991). Theory of instruction: Principles and applications (Rev. ed.). ADI Press.

Engelmann, S., \& Carnine, D. (2011). Could John Stuart Mill have saved our schools? Attainment Co.

Heward, W. L., Kimball, J. W., Heckaman, K. A., \& Dunne, J. D. (2021). In his own words: Siegfried Engelmann talks about what's wrong with education and how to fix it. Behavior Analysis in Practice. https://doi.org/10.1007/s40617-021-00636-x

Heward, W. L., \& Twyman, J. S. (Guest Editors). (2021). Special section on Direct Instruction. Behavior Analysis in Practice.

Marchand-Martella, N. E., Kinder, D., \& Kubina, R. (2005). Special education and direct instruction: An effective combination. Journal of Direct Instruction, 5(1), 1-36.

Sherman, J., Richardson, J., \& Vedora, J. (2021). The use of behavioral skills training to teach components of Direct Instruction. Behavior Analysis in Practice. https://doi.org/10.1007/s40617-021-00594-4

Skinner, B. F. (1968). The technology of teaching. Appleton-Century-Crofts.

Stockard, J., Wood, T. W., Coughlin, C., \& Khoury, C. R. (2020). All students can succeed: A half century of research on the effectiveness of Direct Instruction. Lexington Books/Rowman \& Littlefield.

Vidovic, J.L., Cornell, M.C., Frampton, S.E. et al. Adventures in Direct Instruction Implementation: The Devil Is in the Details. Behav Analysis Practice (2021). https://doi.org/10.1007/s40617-021-00616-1

Publisher's Note Springer Nature remains neutral with regard to jurisdictional claims in published maps and institutional affiliations. 